Document downloaded from:

http://hdl.handle.net/10251/81358

This paper must be cited as:

Micó Vicent, B.; Jordán Núñez, J.; Martinez Verdu, FM.; Balart Gimeno, RA. (2017). A combination of three surface modifiers for the optimal generation and application of natural hybrid nanopigments in a biodegradable resin. Journal of Materials Science. 52(2):889-898. doi:10.1007/s10853-016-0384-8.

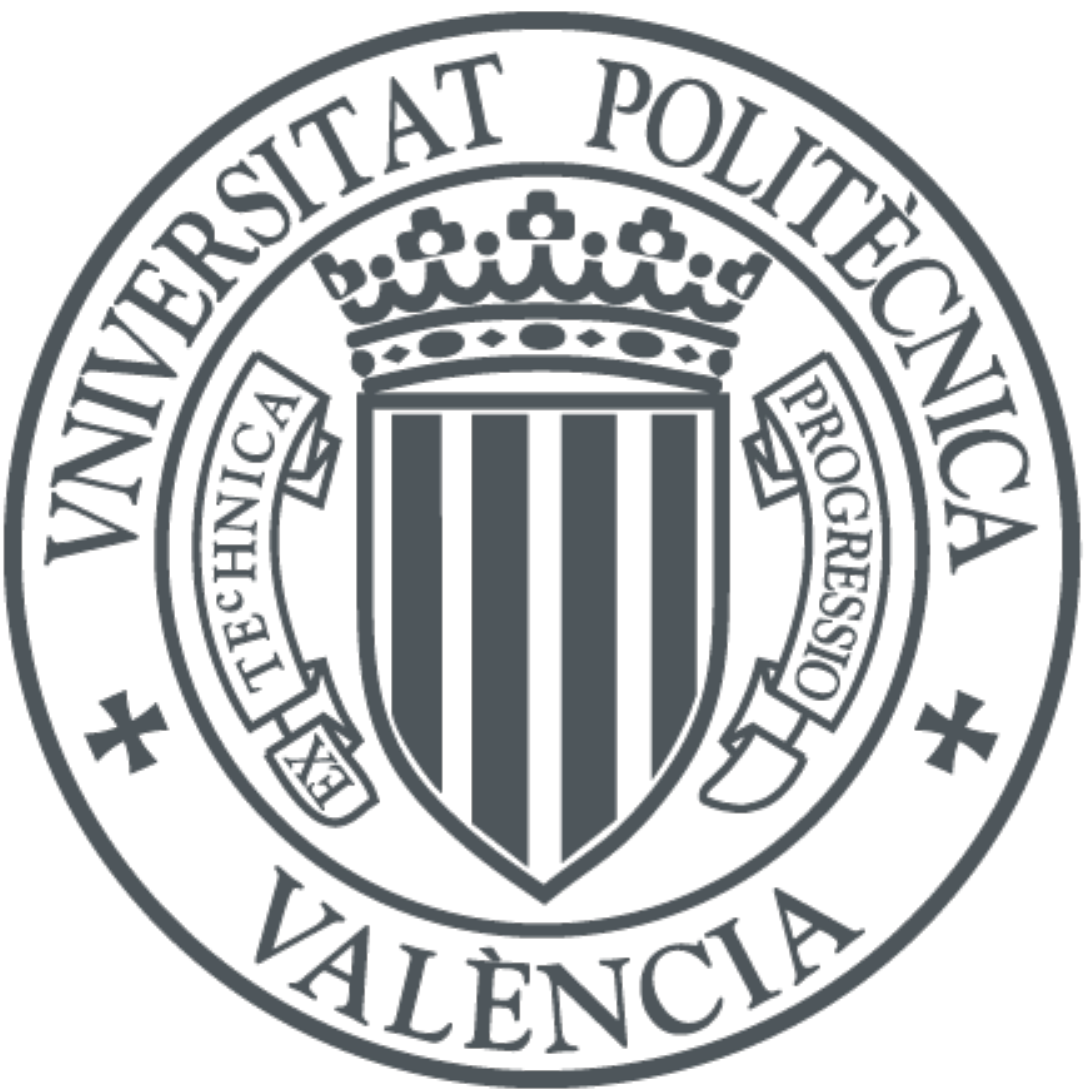

The final publication is available at

http://dx.doi.org/10.1007/s10853-016-0384-8

Copyright Springer Verlag (Germany)

Additional Information 


\title{
A three-surface modifiers combination for the optimal generation and application of natural hybrid nanopigments in a biodegradable resin
}

\author{
Bàrbara Micó-Vicent ${ }^{\mathrm{a}, \mathrm{b}^{*}}$, Jorge Jordán ${ }^{\mathrm{b}}$, Francisco Martínez-Verdúa ${ }^{\mathrm{a}}$, Rafael Balart ${ }^{\mathrm{c}}$ \\ ${ }^{a}$ Colour and Vision Group. University of Alicante, Ctra. San Vicente del Raspeig s/n. 03690. San Vicente \\ del Raspeig (Alicante) Spain. \\ ${ }^{\mathrm{b}}$ Departamento de Estadística e Investigación Operativa Aplicadas y Calidad, Universitat Politècnica de \\ València, Campus d'Alcoi. Pl. Ferràndiz y Carbonell s/n 03801, Alcoy (Alicante) Spain \\ 'Instituto de Tecnología de Materiales, Universitat Politècnica de València, Campus d'Alcoi. Pl. \\ Ferràndiz y Carbonell s/n 03801, Alcoi (Alicante) Spain \\ *Corresponding author. Email: barbara.mico@ua.es (http://web.ua.es/en/gvc)
}

\begin{abstract}
Our purpose was to improve the thermal, mechanical and optimal properties of an epoxy bioresin using optimum hybrid natural pigments previously synthesized in our lab. Next we searched for the best combinations of factors in the synthesis of natural hybrid nanopigments, and then incorporated them into the bioresin. We combined three structural modifiers in the nanopigment synthesis, surfactant, coupling agent (silane) and a mordant salt (alum), selected to replicate mordant textile dyeing with natural dyes. We used Taguchi's design L8 to seek final performance optimisation. We selected three natural dyes, chlorophyll, beta-carotene and beetroot extract, and used two laminar nanoclay types, montmorillonite, and hydrotalcite. The thermal, mechanical and colorimetric characterisation of the composite obtained by mixing natural hybrid nanopigments (bionanocomposite) was made. The natural dye interactions with both nanoclays improved the thermal stabilities, colour performance and UV-VIS light exposure stability of natural dyes and bioresins. The best bionanocomposite materials were found in an acidic $\mathrm{pH}$ [3-4] environment and by modifying nanoclays with mordant and surfactant during the nanopigment synthesis process.
\end{abstract}

\section{Keywords}

A. Nanocomposites, Layered structures, Nanoclays, Hybrid Pigment, Colour fastness, Thermal properties

Abbreviations: Cetylpyridinium bromide (CPB), Sodium dodecyl sulphate (SDS), Alum (MORD), Montmorillonite (M), Hydrotalcite (H), Epoxy bio resin (RES), Natural Orange (NO), Natural Red (NR), and Natural Green (NG). 


\section{Introduction}

Different kinds of nanoparticles were used in thermoplastic and thermosetting biopolymers to enhance their thermal, mechanical and structural properties [1,2]. The aim was to obtain exfoliated nanocomposites to achieve maximum improvements in polymer matrix properties [3,4]. Inorganic fillers, e.g. nanoclays, enhanced thermal stability [5], and also improved the barrier [6], flammability [7] and mechanical properties[8] of both polymers and blends $[9,10]$. To obtain exfoliated polymer composites with nanoclays, the origin of the materials [11], the addition method and compatibilisers must be correctly combined $[12,13]$.

In bionanocomposites, glass transition temperature and crosslink density are higher than the base matrix, and vapour and the UV barrier can also improve with nanoparticles [14]. Growing interest is being shown in bionanocomposites that simultaneously exhibit the controlled release capacity of an antimicrobial extract in active antimicrobial food biopackaging applications [15]. We aimed to contribute knowledge on the improvements of the optical properties of biopolymers using nanoclays naturally modified with natural dyes to obtain coloured bionanocomposites that offer improved mechanical and temperature properties, and also better UV-VIS light exposure colour resistance.

For modifications made to nanoclays in order to improve their compatibility with a different matrix, or to obtain high-performing hybrid nanopigments, surfactant [13], silane agents, and also combinations of both components in nanoclay structures, were used [16]. These modifiers can open laminar nanoclay structures and improve their exchange capacity. Organoclays have proven more compatible with a polymer matrix $[17,18]$. For this reason, we combined two modifiers or more in different laminar nanoclays to improve both their adsorption dye capacity (dyeability) and application performance. We attempted to work basically with natural ingredients in bionanocomposite formulations. We added a mordant salt as a modifier in the possible combination of nanoclay modifiers. We intended to identify each type of relevant nanoclay modifier individually using different natural dyes, and to also see the synergy between the ternary combination of these compounds. 
Design of Experiments (DoE) is key to obtain as much information as possible with as few samples as possible [19]. We used DoE to find the best synthesis factor in nanopigments from different natural dyes to maximise the adsorption dye capacity of different laminar nanoclays and to maximise the protection of thermal natural dyes, and also in the bioresin application to accomplish maximum performance with the best thermal, mechanical, colour stability performance of the final bionanocomposites.

\section{Experimental}

\subsection{Materials}

We selected three natural dyes as our natural hybrid nanopigments: beetroot red extract (NR) CI.75840 $\left(\mathrm{C}_{24} \mathrm{H}_{26} \mathrm{~N}_{2} \mathrm{O}_{13}\right), \beta$-carotene (NO) CI.75130 $\left(\mathrm{C}_{40} \mathrm{H}_{56}\right)$ and copper chlorophyll (NG) CI.75810 $\left(\mathrm{C}_{34} \mathrm{H}_{31} \mathrm{CuN} 4 \mathrm{Na}_{3} \mathrm{O}_{6}\right)$, supplied by Sensient ${ }^{\circledR}$. We used two laminar nanoclays: montmorillonite, under trade name Gel White from Southern Clay Products; and hydrotalcite BioUltra anhydrous, $\geq 99.0 \%$, both with a different charge ion capacity, and supplied by Sigma-Aldrich.

Surfactants were cetylpyridinium bromide (CPB) CAS: 202869-92-9, $\mathrm{C}_{21} \mathrm{H}_{38} \mathrm{BrN} \cdot 6 \mathrm{H}_{2} \mathrm{O}, 384.44 \mathrm{~g} / \mathrm{mol}$, and sodium dodecyl sulphate (SDS) CAS: 151-21-3, $\mathrm{CH}_{3}\left(\mathrm{CH}_{2}\right)_{11} \mathrm{OSO}_{3} \mathrm{Na}, 288.38 \mathrm{~g} / \mathrm{mol}$. We used a mordant salt, potassium alum $\mathrm{AlK}\left(\mathrm{SO}_{4}\right)_{2} \cdot 12 \mathrm{H}_{2} \mathrm{O}$, CAS 7784-24-9, $474.39 \mathrm{~g} / \mathrm{mol}$, and the coupling agent was (3-Aminopropyl) triethoxysilane $\mathrm{H}_{2} \mathrm{~N}\left(\mathrm{CH}_{2}\right)_{3} \mathrm{Si}\left(\mathrm{OCH}_{3}\right)_{3}, \mathrm{CAS}: 13822-56-5,179.29 \mathrm{~g} / \mathrm{mol}$. Finally, in order to record any $\mathrm{pH}$ changes during the synthesis process, hydrochloric acid $(\mathrm{HCl})$, ACS reagent, was used at $37 \%$. All these agents were supplied by Sigma-Aldrich.

For bionanocomposite generation, we used the bioresin whose trade name is GreenPoxy 55, an epoxy system with a single hardener where $55 \%$ of the molecular structure is of plant origin. Catalyst SD 505 came from SICOMIN Composites.

\subsection{Synthesis method}

For nanopigment synthesis, we followed the water/organic solvent dispersion method [20]. In this case, clays were dispersed at 1,500 rpm for $24 \mathrm{~h}$. Clay dispersions were prepared at $25 \mathrm{~g} / \mathrm{L}$ in distilled water and ethanol (50/50), and $\mathrm{pH}$ was adjusted to $4-5$ with $\mathrm{HCl}$. The dye concentration in solutions was $1 \cdot 10^{-}$ 
${ }^{03} \mathrm{M}$ in the three natural dyes, and $0.27 \mathrm{ml} / 1 \mathrm{ml}$ of clay dispersion was added. Modifiers were added before adding dyes at $1 \%$ over clay mass. Dye exchange was performed by stirring at $1,500 \mathrm{rpm}$ at room temperature for $1 \mathrm{~h}$, and at $600 \mathrm{rpm}$ for $24 \mathrm{~h}$. Solvent separation was performed by centrifuging to obtain the paste-nanopigment. Then we washed the paste-nanopigment 3 times by re-dispersing its paste at 400 rpm for 30 minutes. Finally, the paste-nanopigment was cool-dried in an ALPHA 1-2 LDplus lyophilizer for $24 \mathrm{~h}$.

\subsection{Design of experiments}

The experiments were followed by combining the different synthesis factors in the order in the Taguchi L8 experiment (Table 1). There were three replicates for each experiment, one per natural dye. Block assignments were: 1 for the Natural Green (NG), 2 for the Natural Orange (NO) and 3 for the Natural Red (NR) results.

Table 1. Taguchi's L8 design for analysing the presence (1) or absence (-1) of modifiers, clay origin, hydrotalcite (1) or montmorillonite (-1), and pH conditions, natural (1), or acid (-1)

\begin{tabular}{|c|c|c|c|c|c|}
\hline $\mathrm{N}^{\circ}$ & Surfactant & Mordant & Clay & $\mathrm{pH}$ & Silane \\
\hline 1 & 1 & -1 & -1 & 1 & -1 \\
2 & -1 & -1 & 1 & 1 & 1 \\
3 & 1 & 1 & -1 & 1 & 1 \\
4 & 1 & 1 & 1 & -1 & -1 \\
5 & 1 & -1 & 1 & -1 & 1 \\
6 & -1 & -1 & -1 & -1 & -1 \\
7 & -1 & 1 & -1 & -1 & 1 \\
8 & -1 & 1 & 1 & 1 & -1 \\
\hline
\end{tabular}

\subsection{Biocomposite generation}

The biocomposite materials were handmade by mixing with the commercially recommended catalyst, and using silicon templates to obtain plain rectangular samples. We employed different nanopigment concentrations, $10 \%$ (Fig. 1), 5\%, 2\% and 1\%, over the bioresin mass. The curing process was carried out at $90^{\circ} \mathrm{C}$ for $1 \mathrm{~h}$ 


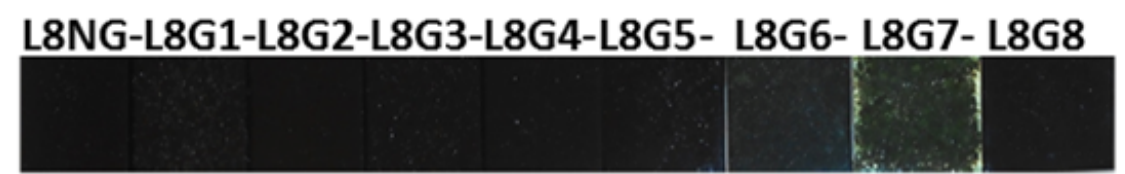

\section{L8NO-L8O1- L802-L803- L804- L805-L806-L807-L808}

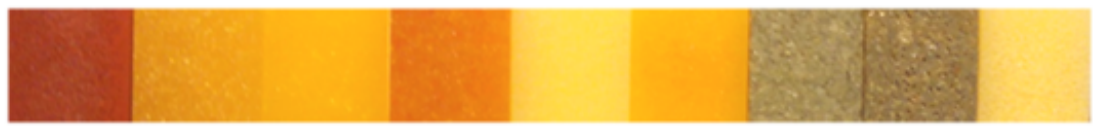

L8NR- L8R1- L8R2- L8R3 -L8R4 -L8R5- L8R6 -L8R7 -L8R8

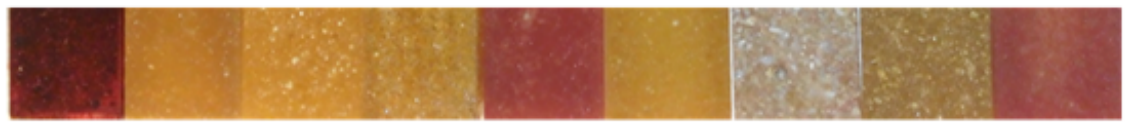

Fig. 1. Maximum concentrated samples for the biocomposite materials from the L8 nanopigments with three natural dyes: NG, NO and NR.

\subsection{Characterisation}

To analyse the synthesis performance of nanopigments, we used the amount of dye that was intercalated in the nanoclay system. For this response, we used a UV-VIS transmission spectrophotometer (JASCO V650) to calculate the dye concentration in the separate supernatants. Then we employed the dye adsorbed over the initially added dye (\%) as a response to maximise the DoE analysis.

We utilised the TGA/SDTA 851 (Mettler-Toledo Inc) equipment to know the degradation temperature of the composite materials (Td). The experimental conditions were a temperature ramp of $5^{\circ} \mathrm{C} / \mathrm{min}$ within the $[20-900]^{\circ} \mathrm{C}$ interval with oxidant medium $\mathrm{N}_{2}: \mathrm{O}_{2}(4: 1)$.

For the mechanical characterisation of the composite materials, toughness was obtained following standard UNE-EN ISO 179-1:2011. Plastics - Determination of Charpy impact properties - Part 1: Noninstrumented impact test (ISO 179-1:2010). The equipment used was a Charpy's pendulum (Metrotec SA).

For the optical properties, we used a Konica Minolta sphere integrated spectrophotometer (CM-2600d) to obtain the reflectance factors $\rho(\lambda)$ for the bionanocomposites within the [370-740] nm range with the D65 illuminant and the CIE-1964 standard observer. We also used a SOLARBOX 1500e RH climatic chamber to measure colour stability against accelerated UV-VIS exposure. Samples were measured within different exposure time intervals, and colour differences were calculated by measuring samples before 
and after radiation exposure. Colour differences $\Delta \mathrm{E}_{\mathrm{ab}} *$ were calculated with the colorimetric attributes of the CIELAB colour space, used as a response to minimise in the DoE analysis.

\section{Results and Discussion}

\subsection{Adsorption}

Dye adsorption was calculated as a percentage of the initially added dye in nanoclay dispersion. With the supernatants separated during the centrifuging process, the adsorption (\%) of each natural dye was obtained under the L8 conditions (Table 2).

Table 2. Adsorbed dye (\%) from that initially added for the chlorophyll (NG), b-carotene (NO) and beetroot (NR) natural dyes under the L8 conditions

\begin{tabular}{|c|l|l|l|}
\hline \multirow{2}{*}{} & \multicolumn{3}{|c|}{ Dye adsorption (\%) } \\
\hline L8 experiment & \multicolumn{2}{|c|}{ NG } & NO \\
\hline 1 & 66.04 & 71.02 & 88.73 \\
2 & 75.66 & 63.39 & 83.64 \\
3 & 75.66 & 69.69 & 88.22 \\
4 & 86.89 & 68.11 & 86.13 \\
5 & 89.45 & 45.71 & 82.71 \\
6 & 100.00 & 99.25 & 98.96 \\
7 & 100.00 & 98.40 & 99.30 \\
8 & 94.37 & 67.74 & 87.06 \\
\hline
\end{tabular}

We used these results as a response to maximise in the DoE analysis. The significant factors in the adsorption response were the presence of the surfactant and silane, and their AE interaction (Fig. 2). The $\mathrm{AE}$ interaction was strong, and the maximum adsorption level was obtained when silane and surfactant modifiers were present (Fig. 3).

The adsorption process depended on the natural dye structure. The best results were obtained with the red dye (NR), then with the green dye (NG), and finally with the natural orange dye (NO). Significant differences appeared only between Blocks 3 and 2 (dyes NR and NO) (Fig. 4). 


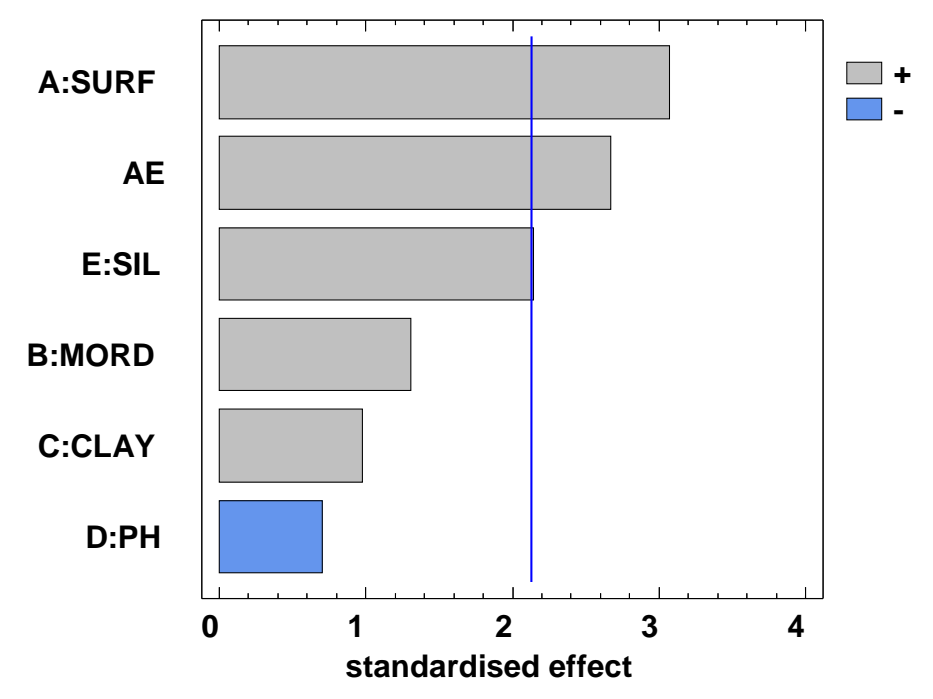

Fig. 2. Pareto's plot for adsorption response (\%) of the three dyes according to the synthesis factors: presence (+) or absence (-) of surfactant (SURF), silane (SIL), and mordant (MORD), pH conditions (PH) acid (-) or natural (+), and nanoclay (CLAY) montmorillonite (-) or hydrotalcite (+).

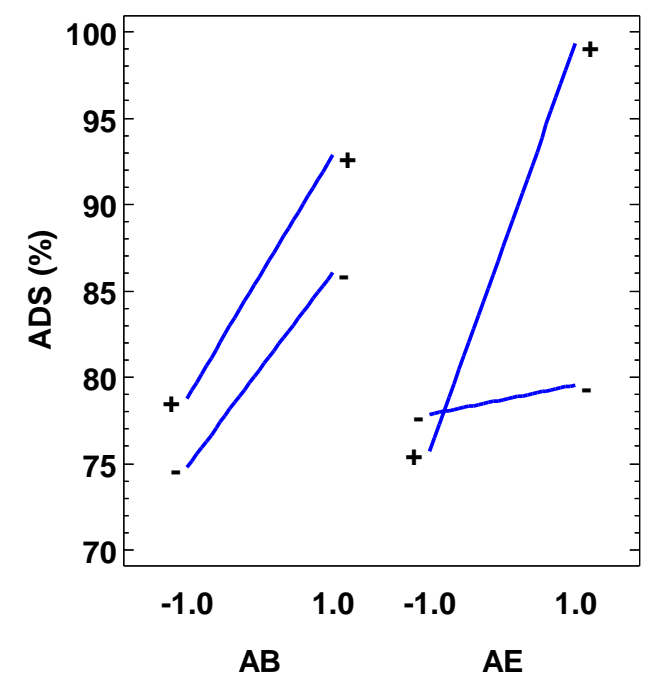

Fig. 3. Interactions plot for the surfactant and mordant $A B$, or silane $A E$ interactions effects on the adsorption $(\%)$ of the three natural dyes. 


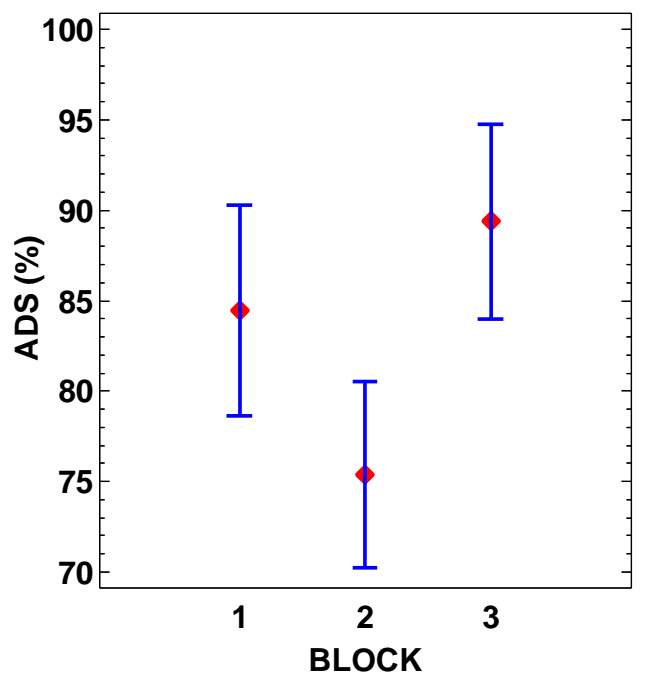

Fig. 4. Means plot for adsorption (\%) according to dye (BLOCK): 1-NG, 2-NO, 3-NR.

We expected nanoclay to be a significant factor because the selected natural dyes were anionic. However, the surfactant-silane modifiers allowed adsorption in both nanoclays because of nanoclay interlayer and surface modifications [21]. Performance during the synthesis process under these conditions depended only on the molecular structure of the natural dyes, e.g. aggregation, orientations and charge density $[22,21]$.

\subsection{Degradation temperature}

Fig. 5 shows the first derivate of mass loss from the biocomposites with $5 \%$ of montmorillonite and hydrotalcite. Both nanoclays reinforced the bioresin against temperature degradation (Td), as seen in the peaks shifts.

Reinforcement of materials became more pronounced when the composite load was a nanopigment, as the graphical example with the nanopigments from chlorophyll and montmorillonite illustrates. Differences were observed among biocomposites according to synthesis conditions (Fig. 6). 


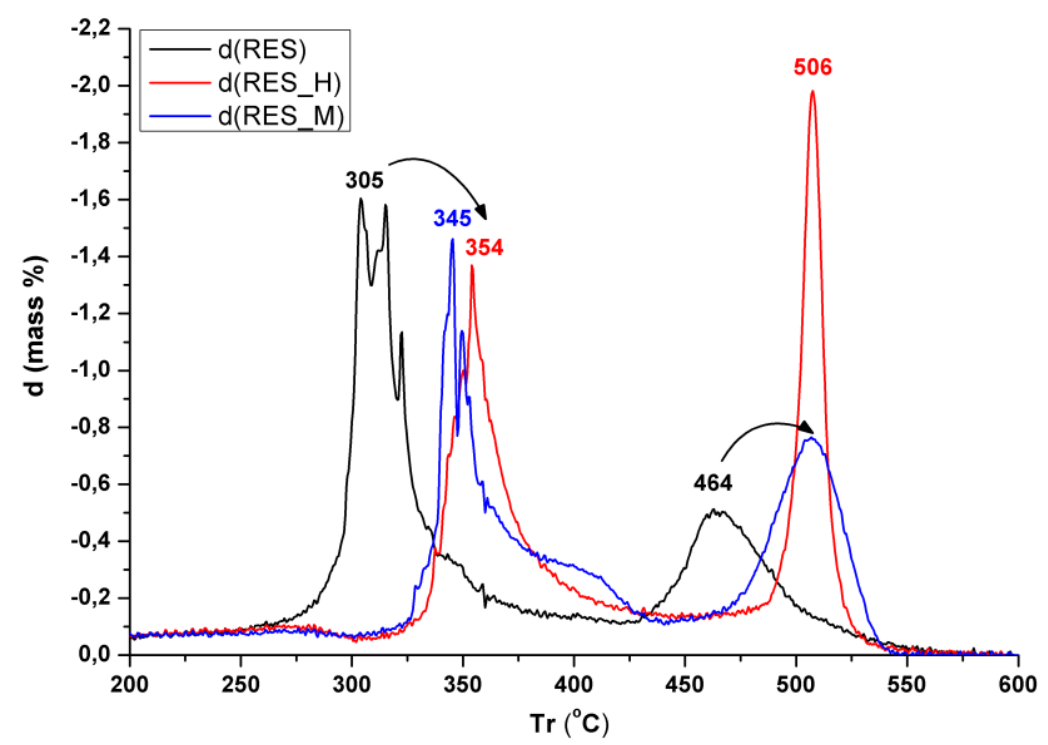

Fig. 5. First derivate curves of mass degradation curves d(mass\%) for original bioresin (RES), and composites with 5\% of montmorillonite (RES_M) and hydrotalcite (RES_H).

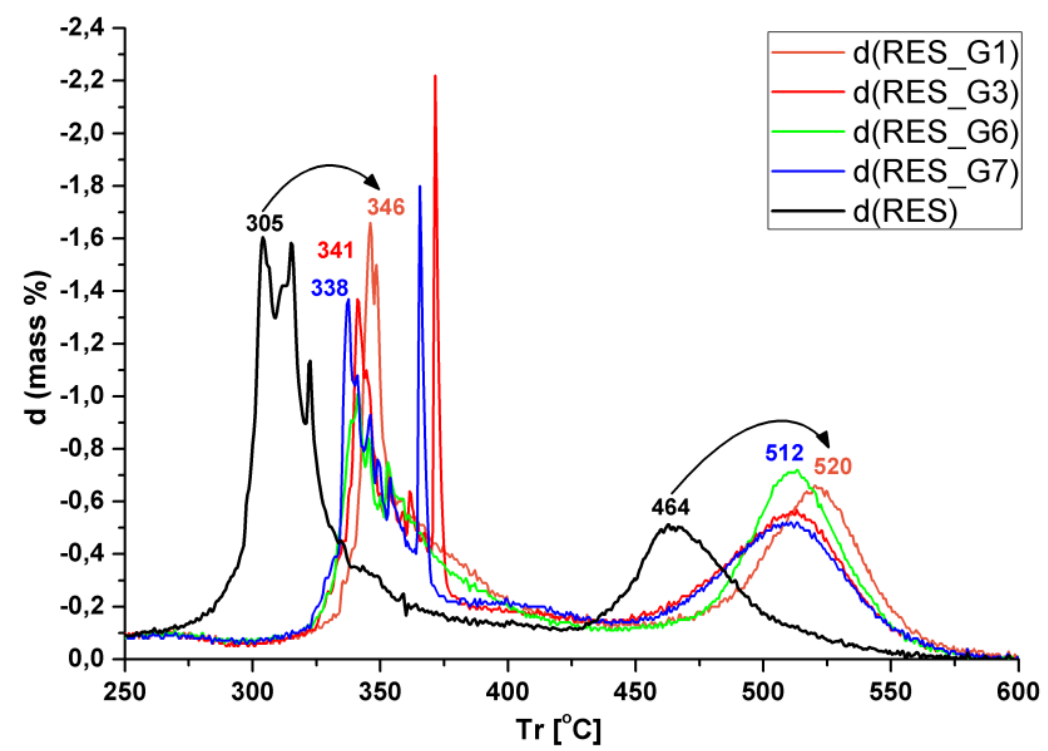

Fig. 6. First derivate curves of the mass degradation curves d(mass \%), for the original bioresin (RES), and composites with 5\% of nanopigments loads from chlorophyll and montmorillonite clay RES_[G1,G3,G6,G7]. 


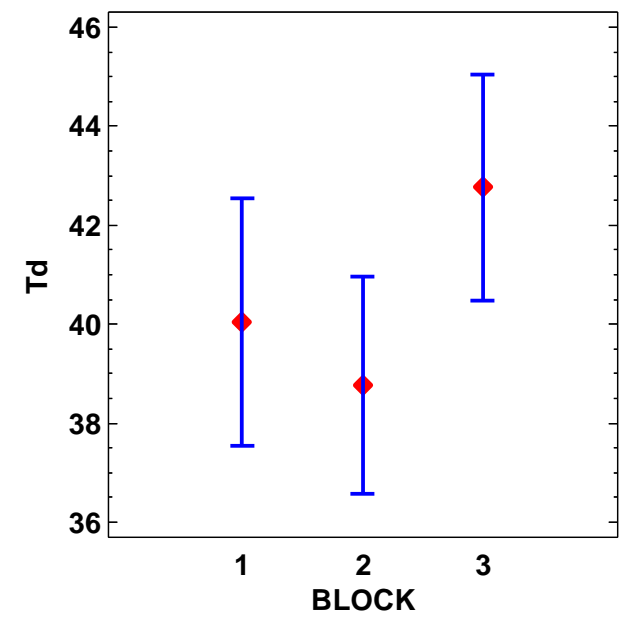

Fig. 7. Means plot for the composites degradation temperature according to dye (BLOCK): 1-NG, 2-NO, 3-NR.

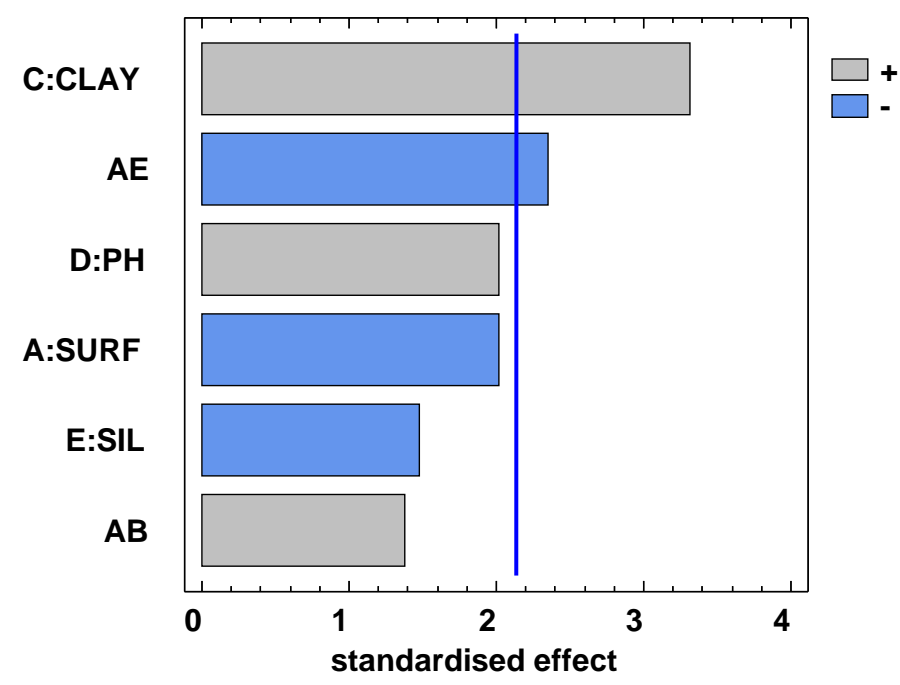

Fig. 8. Pareto's plot for three blocks of biocomposites with the Td response according to synthesis factors: presence (+) or absence (-) of surfactant (SURF), silane (SIL), and mordant (MORD), pH conditions (PH) acid (-) or natural (+), and nanoclay (CLAY) montmorillonite (-) or hydrotalcite (+).

In order to answer the question about the optimal conditions for achieving maximum temperature reinforcement, we used the Td increment for the original bioresin as a response in the DoE. We observed no differences between the natural dyes used as blocks (Fig. 7). The significant factors under the nanopigments conditions were nanoclays, and the surfactant and silane interactions (AE). However, we had to consider the $\mathrm{pH}$ and individual surfactant effects because they came close to being considered 
significant. The biggest Td increment in bioresin was obtained using hydrotalcite, natural $\mathrm{pH}$ and only the silane modifier. The surfactant effect was negative on these responses (Fig. 8). The coupling agent effect (silane) worked better individually, and the interaction between epoxy chains and nanoclay particles was stronger than when the surfactant was present.

\subsection{Toughness}

We chose the toughness $\left(\mathrm{Jcm}^{-2}\right)$ property for mechanical characterisation. As shown in the Figure, the impact of the biocomposites' absorbing capacity was less marked inorganic fillers (5\%) (Fig. 9). We confirmed the conclusions drawn in previous works, in which the mechanical properties of epoxy resins improved by incorporating modified nanoclays (with surfactants and/or silane). However, we did not accomplish the expected improvements of the mechanical properties $[16,23,24]$. This effect can be explained in view of the increments in temperature resistance as they were caused by the impediment of resin vibration chains, or were due to the aggregation formations in the epoxy resin. So we observed stiffness and increased hardness.

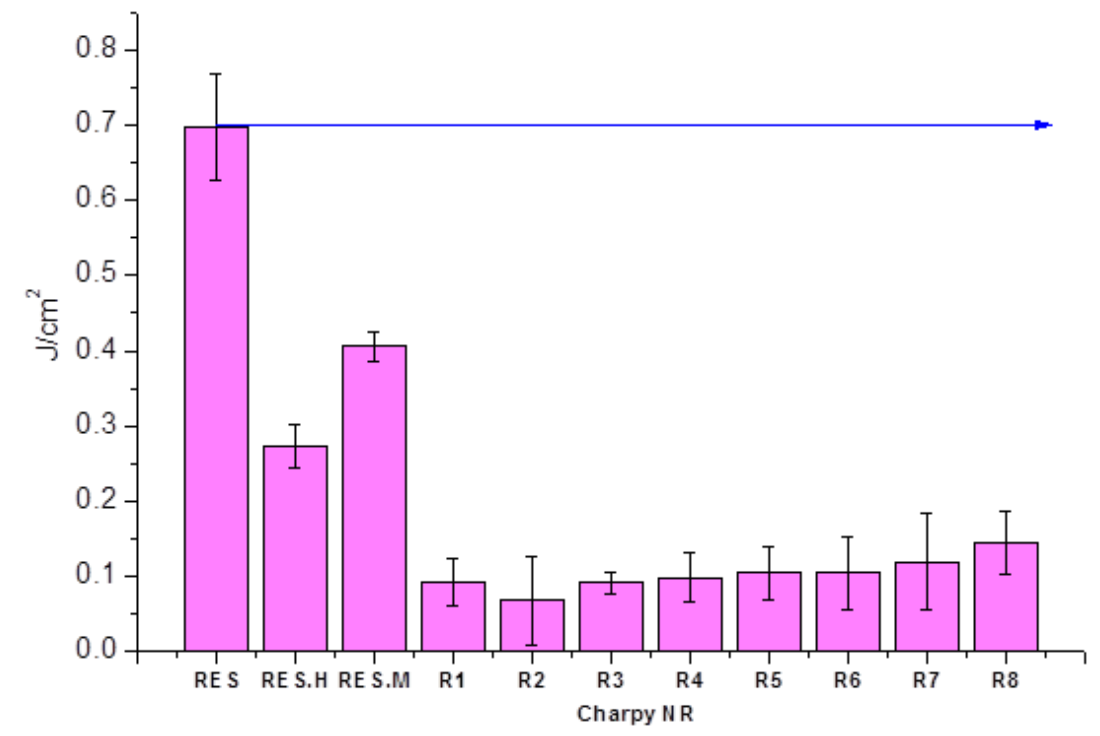

Fig. 9. The toughness results of the Charpy's test of the original bioresin (RES) and composites with 5\% of nanopigments from natural red [R1-R8] and nanoclays (M, H).

We sought the synthesis conditions under which the fragility effect would be minimised from a better exfoliation of the nanoclays sheets in the polymer matrix. The natural dye for which the best toughness 
results were found was the chlorophyll extract (NG). No differences between the NG and the $\beta$-carotene (NO) were noted, but a significant difference was found with the red dye (NR) (Fig. 10). This result is exactly the opposite of the adsorption response. So a decision had to be made about prioritising the adsorption performance or the resistance impact properties in the biocomposites.

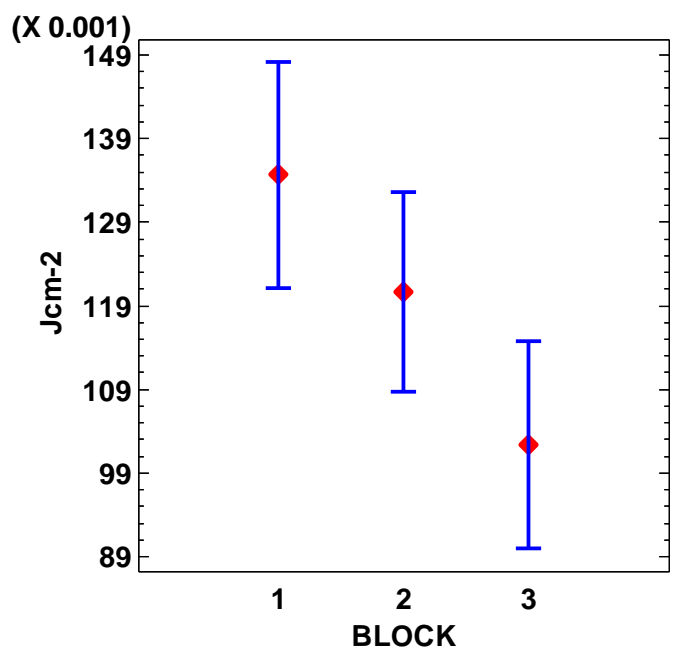

Fig. 10. Means plot for composites toughness $\left(\mathrm{Jcm}^{-2}\right)$ according to dye (BLOCK): 1-NG, 2-NO, 3-NR.

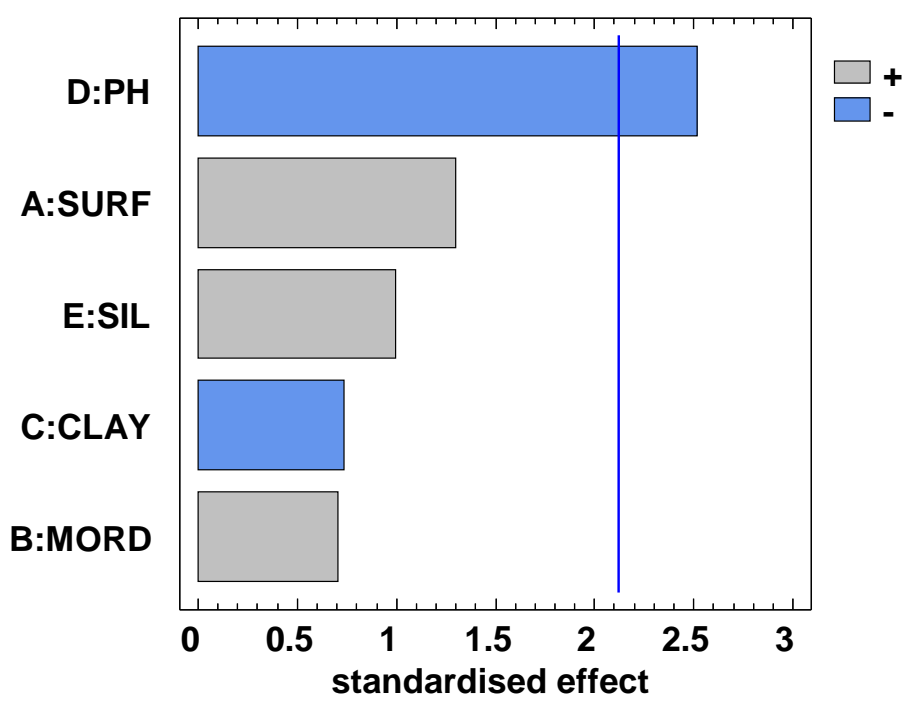

Fig. 11. Pareto's plot for three blocks of biocomposites with a toughness response $\left(\mathrm{Jcm}^{-2}\right)$ according to the synthesis factors: presence (+) or absence (-) of surfactant (SURF), silane (SIL), and mordant (MORD), pH conditions (PH) acid (-) or natural (+), and nanoclay (CLAY) montmorillonite (-) or hydrotalcite (+). 
The only significant synthesis factor that minimised toughness loss was $\mathrm{pH}$. Use of an acidic $\mathrm{pH}[3-4]$ is recommended (Fig. 11). The silanol and aluminol presented on the nanoclay surface [25] at this $\mathrm{pH}$ improved the natural dyes-nanoclay interactions [26], and the exfoliation of more nanopigment sheets in the bioresin.

\subsection{Colour stability with accelerated UV-VIS exposure}

Colour resistance was evaluated through the colour differences calculated in the UV-VIS acceleration test. Test duration was $1,000 \mathrm{~h}$, and measurements were taken at different time intervals. Previous works have checked organic dye stabilisation in nanoclay structures by changes in absorption curves [27]. We calculated the colour difference $\left(\Delta \mathrm{E}_{\mathrm{ab}} *\right)$, and also standardised the calculated values by natural dye content $(\mathrm{g})$ in each sample $\left(\Delta \mathrm{E}_{\mathrm{ab}} * / \mathrm{g}\right.$.dye). Standard errors were also calculated and represented to make comparisons. Fig. 12 evidences the enhancement of bioresin colour efficiency using nanopigments instead of the original dyes. The three natural dyes had lost their colour by the end of the test, while nanopigments still presented minor colour differences $\left(\Delta \mathrm{E}_{\mathrm{ab}} *<2\right.$ units). To maximise colour resistance under UV-VIS radiation, we used the colour differences in the biocomposites for the DoE analysis. The nanopigment block with the least colour differences was NR, followed by NG, and finally by the biggest differences in the nanopigments with NO. Mean differences did not exceed the detection threshold accepted in colour industries of 2-3 units of $\Delta \mathrm{E}_{\mathrm{ab}} *$ in any case [28,29]. 


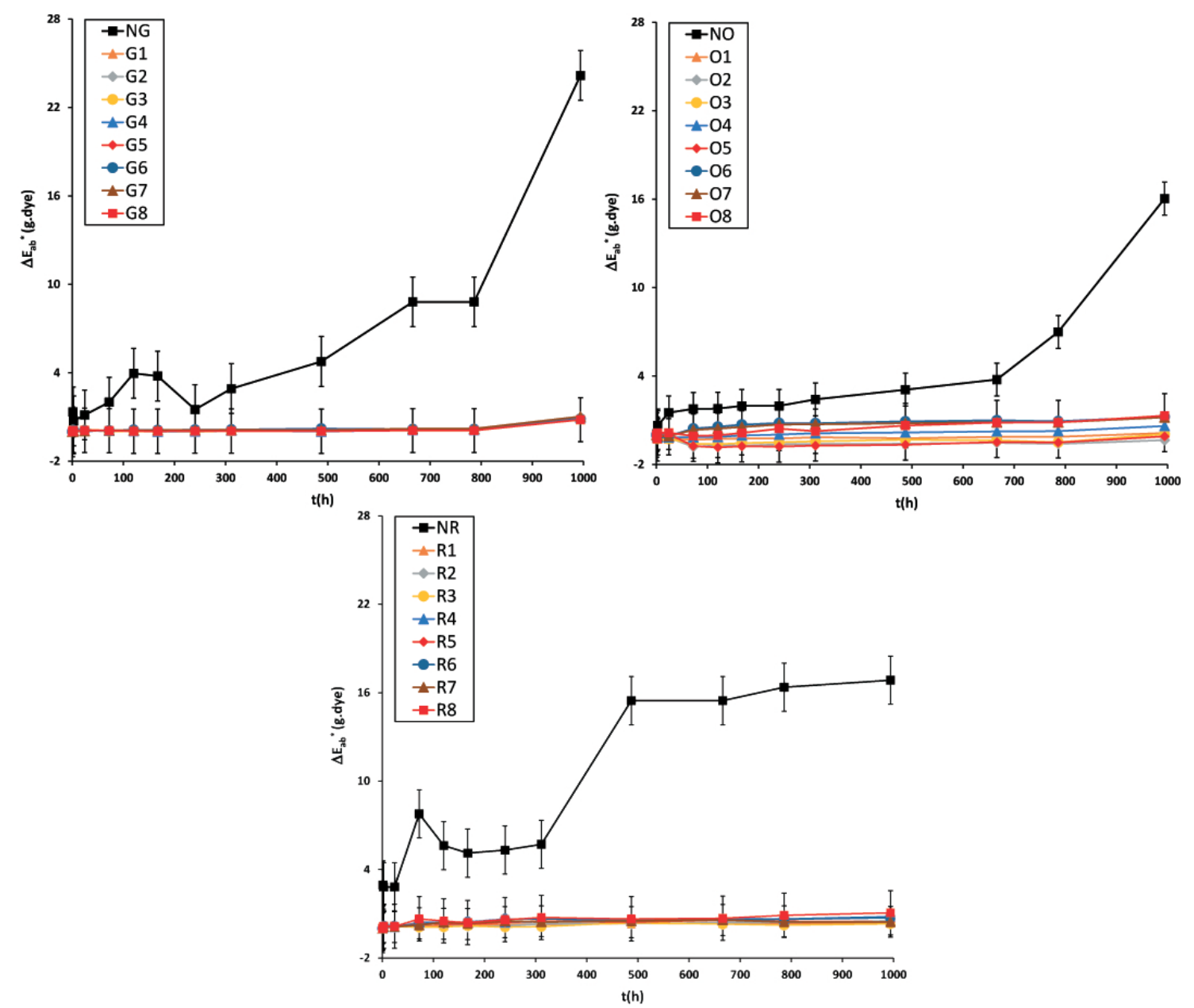

Fig. 12. $\Delta \mathrm{E}_{\mathrm{ab}} * / \mathrm{g}$. dye for biocomposites with the three natural dyes $\mathrm{NG}, \mathrm{NO}$ and $\mathrm{NR}$, and the nanopigments synthesised under the L8 conditions.

To obtain the lowest value in the $\Delta \mathrm{E}_{\mathrm{ab}} *$ response, the significant factors were surfactant and nanoclay. To ensure the least colour degradation, hydrotalcite had to be used with the surfactant present, which allowed the nanoclay structure to open by modifying the basal space, and to accomplish strong interactions between the exchanged anions (natural dyes) and the nanoclay [30]. However, mordant and silane modifiers are not significant factors, so their modification effect was not as strong as the surfactant in the protection/encapsulation nanoclay effect (Fig. 13). 


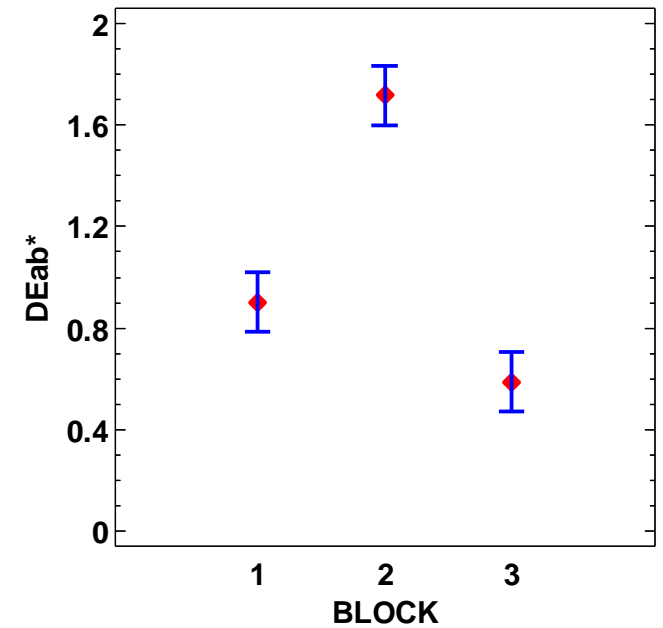

Fig. 13. Means plot for composites colour resistance $\left(\Delta \mathrm{E}_{\mathrm{ab}} * / \mathrm{g}\right.$.dye) according to dye (BLOCK): 1-NG, 2NO, 3-NR.

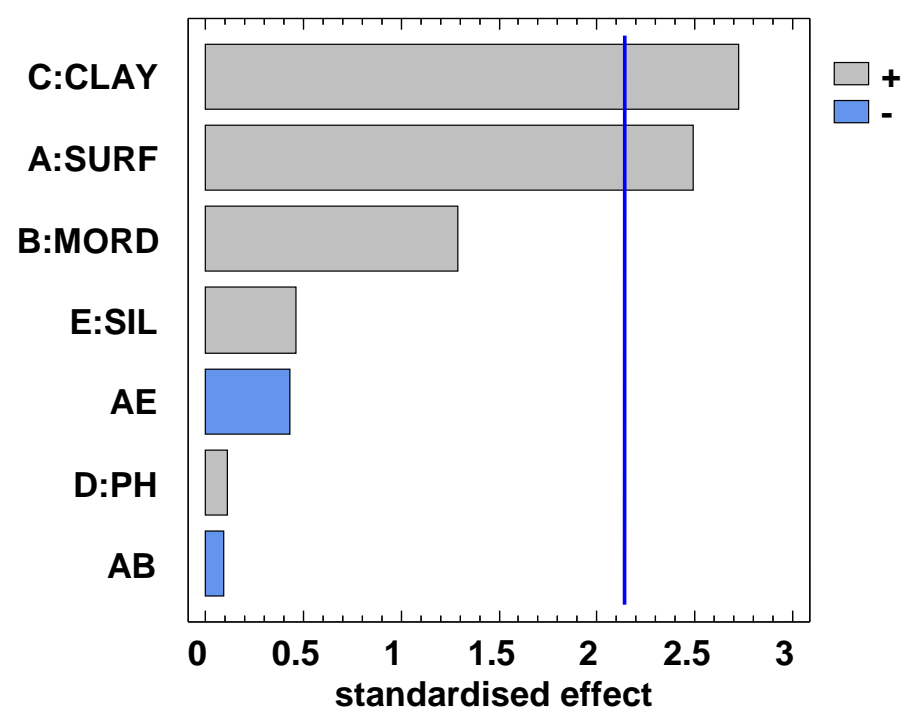

Fig. 14. Pareto's plot for three blocks of biocomposites with colour resistance $\left(\Delta \mathrm{E}_{\mathrm{ab}} * / \mathrm{g}\right.$.dye $)$ according to the synthesis factors: presence (+) or absence (-) of surfactant (SURF), silane (SIL), and mordant (MORD), pH conditions (PH) acid (-) or natural (+), and nanoclay (CLAY) montmorillonite (-) or hydrotalcite (+).

\section{Conclusions}

We synthesised nanopigments from three different natural dyes and obtained composite materials with an epoxy bioresin, in some cases with homogeneous and intense colours because of improvements in the 
natural dyes and epoxy bioresin interactions. The best results were obtained in adsorption performance using the red nanopigments from the beetroot extract (NR). The temperature and UV-VIS colour stability of biocomposites also improved. According to the toughness results, the best behaviour was accomplished with the green composites from chlorophyll (NG). So natural dye structures are closely related to the final properties of coloured biocomposites.

While attempting to strike a balance between nanopigment synthesis and biocomposite performance, the levels selected from the tested factor were: use of surfactant and silane under acid $\mathrm{pH}$ conditions [3-4] with a hydrotalcite nanoclay. The silane and surfactant interaction must be considered positive during natural dye adsorption, but negative at the biocomposite's degradation temperature. The degradation temperature was higher than the original bioresin for all the synthesis conditions, but using silane and surfactant together should be avoided if the maximum degradation temperature is to be achieved, which obviously depends on the final industrial application.

The mordant factor was not significant in any analysis, and the recommended level was positive in all the tests. Thus their use will have no negative impact on either nanopigment synthesis or biocomposite performance.

\section{Acknowledgement}

We thank the Spanish Ministry of Economy and Competitiveness for funding Projects DPI2011-30090C02-02 and DPI2015-68514-R.

\section{References}

1. Majdzadeh-Ardakani K, Nazari B (2010) Improving the mechanical properties of thermoplastic starch/poly(vinyl alcohol)/clay nanocomposites. Composites Science and Technology 70 (10):1557-1563. doi:http://dx.doi.org/10.1016/j.compscitech.2010.05.022 2. Najafi N, Heuzey MC, Carreau PJ (2012) Polylactide (PLA)-clay nanocomposites prepared by melt compounding in the presence of a chain extender. Composites Science and Technology 72 (5):608-615. doi:http://dx.doi.org/10.1016/j.compscitech.2012.01.005 3. Acharya H, Srivastava SK, Bhowmick AK (2007) Synthesis of partially exfoliated EPDM/LDH nanocomposites by solution intercalation: Structural characterization and 
properties. Composites Science and Technology 67 (13):2807-2816.

doi:http://dx.doi.org/10.1016/j.compscitech.2007.01.030

4. Marras SI, Zuburtikudis I, Panayiotou C (2007) Nanostructure vs. microstructure:

Morphological and thermomechanical characterization of poly(L-lactic acid)/layered silicate hybrids. European Polymer Journal 43 (6):2191-2206. doi:10.1016/j.eurpolymj.2007.03.013 5. Leszczyńska A, Njuguna J, Pielichowski K, Banerjee JR (2007) Polymer/montmorillonite nanocomposites with improved thermal properties: Part I. Factors influencing thermal stability and mechanisms of thermal stability improvement. Thermochimica Acta 453 (2):75-96. doi:http://dx.doi.org/10.1016/j.tca.2006.11.002

6. Park HM, Lee WK, Park CY, Cho WJ, Ha CS (2003) Environmentally friendly polymer hybrids - Part I - Mechanical, thermal, and barrier properties of thermoplastic starch/clay nanocomposites. Journal of Materials Science 38 (5):909-915. doi:10.1023/a:1022308705231 7. Porter D, Metcalfe E, Thomas MJK (2000) Nanocomposite fire retardants - A review. Fire and Materials 24 (1):45-52. doi:10.1002/(sici)1099-1018(200001/02)24:1<45::aidfam719>3.0.co;2-s

8. Ray SS, Okamoto M (2003) Polymer/layered silicate nanocomposites: a review from preparation to processing. Progress in Polymer Science 28 (11):1539-1641. doi:DOI 10.1016/j.progpolymsci.2003.08.002

9. Gao D, Li R, Lv B, Ma J, Tian F, Zhang J (2015) Flammability, thermal and physicalmechanical properties of cationic polymer/montmorillonite composite on cotton fabric. Composites Part B: Engineering 77:329-337. doi:http://dx.doi.org/10.1016/j.compositesb.2015.03.061

10. LeBaron PC, Wang Z, Pinnavaia TJ (1999) Polymer-layered silicate nanocomposites: an overview. Applied Clay Science 15 (1-2):11-29. doi:10.1016/s0169-1317(99)00017-4 11. Karuntarut Sermsantiwanita SP (2012) Preparation of bio-based nanocomposite emulsions: Effect of clay type. Progress in Organic Coatings 74:660- 666

12. Pascual J, Fages E, Fenollar O, Garcia D, Balart R (2009) Influence of the compatibilizer/nanoclay ratio on final properties of polypropylene matrix modified with montmorillonite-based organoclay. Polymer Bulletin 62 (3):367-380. doi:10.1007/s00289-0080018-7

13. Beltrán MI, Benavente V, Marchante V, Marcilla A (2013) The influence of surfactant loading level in a montmorillonite on the thermal, mechanical and rheological properties of EVA nanocomposites. Applied Clay Science 83-84 (0):153-161.

doi:http://dx.doi.org/10.1016/j.clay.2013.08.028

14. Bitinis N, Verdejo R, Maya EM, Espuche E, Cassagnau P, Lopez-Manchado MA (2012) Physicochemical properties of organoclay filled polylactic acid/natural rubber blend bionanocomposites. Composites Science and Technology 72 (2):305-313.

doi:http://dx.doi.org/10.1016/j.compscitech.2011.11.018

15. Sanchez-Garcia MD, Lopez-Rubio A, Lagaron JM (2010) Natural micro and nanobiocomposites with enhanced barrier properties and novel functionalities for food biopackaging applications. Trends in Food Science \& Technology 21 (11):528-536. doi:http://dx.doi.org/10.1016/j.tifs.2010.07.008

16. Huskić M, Žigon M, Ivanković M (2013) Comparison of the properties of clay polymer nanocomposites prepared by montmorillonite modified by silane and by quaternary ammonium salts. Applied Clay Science 85 (0):109-115. doi:http://dx.doi.org/10.1016/j.clay.2013.09.004 17. Osman MA, Rupp JEP, Suter UW (2005) Effect of non-ionic surfactants on the exfoliation and properties of polyethylene-layered silicate nanocomposites. Polymer 46 (19):8202-8209. doi:10.1016/j.polymer.2005.06.101

18. Wang H, Fang P, Chen Z, Wang S, Xu Y, Fang Z (2008) Effect of silane grafting on the microstructure of high-density polyethylene/organically modified montmorillonite nanocomposites. Polymer International 57 (1):50-56. doi:10.1002/pi.2310 19. Montgomery DC (2008) Design and analysis of experiments. John Wiley \& Sons, 
20. Baena-Murillo, E. Micó-Vicent, B., Martínez-Verdú, F.M. (2013) Method for the synthesis of nanostructured hybrid pigments having properties that can be syntonized.

21. Kohno Y, Inagawa M, Ikoma S, Shibata M, Matsushima R, Fukuhara C, Tomita Y, Maeda Y, Kobayashi K (2011) Stabilization of a hydrophobic natural dye by intercalation into organomontmorillonite. Applied Clay Science 54 (3-4):202-205. doi:10.1016/j.clay.2011.09.001 22. Kaneko Y, Iyi N, Bujdak J, Sasai R, Fujita T (2004) Effect of layer charge density on orientation and aggregation of a cationic laser dye incorporated in the interlayer space of montmorillonites. Journal of Colloid and Interface Science 269 (1):22-25. doi:10.1016/s00219797(03)00602-7

23. Silva AA, Dahmouche K, Soares BG (2011) Nanostructure and dynamic mechanical properties of silane-functionalized montmorillonite/epoxy nanocomposites. Applied Clay Science 54 (2):151-158. doi:http://dx.doi.org/10.1016/j.clay.2011.08.002

24. Park S-J, Kim B-J, Seo D-I, Rhee K-Y, Lyu Y-Y (2009) Effects of a silane treatment on the mechanical interfacial properties of montmorillonite/epoxy nanocomposites. Materials Science and Engineering: A 526 (1-2):74-78. doi:http://dx.doi.org/10.1016/j.msea.2009.07.023

25. Khraisheh MAM, Al-Ghouti MA, Allen SJ, Ahmad MN (2005) Effect of OH and silanol groups in the removal of dyes from aqueous solution using diatomite. Water Research 39 (5):922-932. doi:10.1016/j.watres.2004.12.008

26. Fahn R, Fenderl K (1983) Reaction-products of organic-dye molecules with acid-treated montmorillonite. Clay Minerals 18 (4):447-458. doi:10.1180/claymin.1983.018.4.10

27. Kohno Y, Totsuka K, Ikoma S, Yoda K, Shibata M, Matsushima R, Tomita Y, Maeda Y, Kobayashi K (2009) Photostability enhancement of anionic natural dye by intercalation into hydrotalcite. Journal of Colloid and Interface Science 337 (1):117-121.

doi:http://dx.doi.org/10.1016/j.jcis.2009.04.065

28. Pascual Capilla JMAyJP (2002) Fundamentos de colorimetría.

29. Gilabert EJ (2007) Color psicofísico. In: Valencia Upd (ed) Medida del color. pp 185-221 30. Zhao H, Nagy KL (2004) Dodecyl sulfate-hydrotalcite nanocomposites for trapping chlorinated organic pollutants in water. Journal of Colloid and Interface Science 274 (2):613624. doi:http://dx.doi.org/10.1016/j.jcis.2004.03.055 